\title{
EL CAMINO A LA DIVERSIDAD MUNICIPAL
}

\section{THE PATH TO HETEROGENEOUS LOCAL GOVERNMENTS}

\author{
Enrique RABELL GARCÍA*
}

RESUMEN: La reglamentación constitucional del municipio mexicano ha propiciado su unidad institucional y la falta de diversidad gubernamental a pesar de las grandes diferencias culturales, políticas y económicas de los mismos. Los problemas comprenden desde la incapacidad de encauzar formas particulares democráticas, así como las inadecuadas estructuras administrativas y servicios locales que no obedecen a sus necesidades propias. El análisis comparativo señala una correlación inversa entre la falta de reglamentación nacional y la diversidad municipal, presentando mayores ventajas los gobiernos locales bajo regímenes variados. En nuestro caso, la abrogación o derogación parcial del artículo 115 de la ley fundamental originaría la posibilidad de que los constituyentes locales pudieran crear formas diversas para adecuar el gobierno local a las necesidades propias de cada región.

Palabras claves: derecho constitucional, reforma del Estado, gobierno municipal, administración pública.
ABSTRACT: The Mexican local government constitutional text has originated the same institutional framework and, the lack of a government typology even the great cultural, political and economical diversity. The problems go from the inability to pursue local democratic forms to inefficient administrative structures and local services which do not fit citizen needs. The comparative study points a negative correlation between the constitutional text and the presence of several types of local governments, showing more advantages the local governments under different organic structures. In our case, the complete or partial elimination of the article 115 of the national constitution would open the possibility to state congresses to develop different types of local governments which agree with their local necessities in each region.

Descriptors: constitutional law, State reform, local government and, public administration.

\footnotetext{
* Doctor en administración pública, Universidad de Indiana.
} 


\section{LA PROBLEMÁTICA CONSTITUCIONAL DEL MUNICIPIO}

La reforma del estado plantea retos importantes para las estructuras vigentes. En particular las modificaciones que se han introducido al municipio durante el siglo pasado así como los planteamientos actuales apuntan a la modificación del artículo 115 de la Constitución nacional con la finalidad de añadir nuevas atribuciones, competencias o facultades para dotarlo de mayores responsabilidades. Esta tendencia histórica, que efectivamente ha fortalecido el municipio, ha pasado por un lado el hecho de que la excesiva reglamentación ha provocado que los constituyentes estatales se sujeten a un marco estricto en lo político, administrativo y económico, que les impide adecuar el gobierno municipal a las distintas realidades que presentan las regiones, creando así gobiernos municipales que les faltan atribuciones $\mathrm{y}$ en otros casos, aquellos que no pueden ejercer las funciones que les encomienda el texto fundamental.

En México los municipios presentan una gran diversidad en materia geográfica así como en torno a su problemática económica y social. Dicha diversidad contrasta profundamente con el marco constitucional que establece un solo tipo de gobierno municipal sin importar las diferencias ya apuntadas. De tal forma los problemas originados por la falta de una estructura adecuada comprenden: a) la falta de financiamiento propio por no contar con bases impositivas adecuadas; b) la incapacidad para desarrollar y aplicar planes de desarrollo urbano en municipios con poca densidad de población; c) la incapacidad de establecer modalidades de gobierno que permitan a los representantes del ayuntamiento cumplir con responsabilidades políticas o administrativas de acuerdo al perfil social o económico; d) la imposibilidad de adaptar usos y costumbres; y e) el establecimiento de prácticas democráticas locales. ${ }^{1}$

El presente estudio tiene como hipótesis principal demostrar que una reforma que abrogue o derogue parcialmente el artículo 115 de la Constitución nacional, motivaría que los constituyentes de las entidades pudieran introducir formas de gobierno municipal y, en consecuencia, adecuar la forma de gobierno y estructura administrativa a las necesidades propias de cada localidad. Si bien es cierto que esta reforma por si sola no garantiza

Guillen, Tonatiuh, Agenda de la reforma municipal, México, CIDE, 2000, y Merino, Mauricio, Los gobiernos municipales en México: El problema del diseño institucional, documento de trabajo, 145, México, CIDE, abril 2004. 
resolver todos los problemas de los gobiernos locales, si podría representar un primer paso para facilitar la evolución administrativa del mismo.

Para poder contestar a dicho planteamiento se utiliza un enfoque multidisciplinario el cual consta de la parte histórica, socio-económica y jurídica para analizar la viabilidad de introducir la reforma propuesta, así como justificar las ventajas que pudiera tener la introducción de tipologías de gobierno. La parte histórica sirve para comprender que el municipio desde su origen, así como los propios antecedentes en México, siempre ha presentado figuras políticas y administrativas distintas de acuerdo al perfil de cada comunidad. El aspecto comparativo tiene la finalidad de verificar la existencia de diferentes tipos de gobiernos municipales en otras naciones y sus ventajas. En cuanto al análisis jurídico se pretende justificar que la abrogación o derogación del artículo 115 constitucional no producirá la eliminación o falta de validez jurídica para ejercer las funciones que actualmente desarrolla.

El estudio se encuentra dividido en las siguientes partes: antecedentes históricos del municipio; la variedad de gobiernos municipales en otras naciones; los distintos marcos constitucionales y sus efectos sobre el gobierno local; los antecedentes históricos del municipio en México; la situación geográfica y económica de los municipios; el análisis constitucional de la reforma propuesta; y las consideraciones finales respecto de las ventajas de poder introducir la reforma propuesta.

\section{ANTECEDENTES HISTÓRICOS}

Bajo el Imperio romano se origina la reglamentación municipal en virtud de las relaciones políticas y jurídicas frente a los pueblos conquistados. La propia expansión romana es indirectamente responsable de crear diversas formas de municipios al reconocer dos formas de gobierno local. La primera consistía en una relación de sumisión o deditii, la cual consideraba a sus habitantes como súbditos $\mathrm{y}$, al haber entregado sus personas y posesiones al pueblo romano, eran gobernados arbitrariamente por un praefectus.

La segunda relación jurídica se basaba en una alianza o socii, en la cual los habitantes se consideraban aliados y se les denominaba foederati o socii, quienes conservaban su régimen municipal e instituciones políticas; pero en virtud de la fórmula "majestatem populi romani comiter conservato", recibían ciertas órdenes de Roma, como el pago de impuestos o munera y sus magistrados debían rendir cuentas al gobernador de la provincia. Con 
la segunda categoría surgió el municipio propiamente en virtud de configurarse el rasgo fundamental del gobierno local adscrito a una unidad política superior. $^{2}$

Esta última fórmula jurídica representa el primer vestigio de una verdadera tipología municipal. Cuando los romanos permiten a sus socii conservar sus instituciones políticas podemos imaginar que cada pueblo en particular tuviera costumbres políticas diferentes que pudieran subsistir bajo la norma contractual en cuestión. Resulta comprensible que pueblos tan distintos como los judíos, los iberas, numidas, galos, macedonios, etcétera, llegaran a tener instituciones y prácticas de gobierno distintas.

Posteriormente el municipio, como institución subordinada a otro ente político, vuelve a surgir hasta el siglo $\mathrm{X}$, cuando se inicia el conflicto entre la Iglesia, los señores feudales y los reyes. Así como el Imperio romano utilizó la institución municipal para acrecentar sus dominios, los reyes medievales fortalecen las libertades municipales para extender sus dominios y contar con súbditos que garanticen el reclutamiento de sus ejércitos y cobro de impuestos para poder hacer frente a los otros poderes.

En particular el ciclo resulta notorio cuando Carlomagno funda la primera dinastía europea en el siglo IX. Sin embargo,

este proceso no es igual en todo Occidente, ya que hubo variado desarrollo de las ciudades y diversas relaciones entre los estamentos de poder. Por eso existieron distintos regímenes jurídicos según los respectivos países y las etapas históricas. Sin embargo, podemos señalar, especialmente, siguiendo a Reglá Campistol, tres tipos de municipios en el occidente europeo: el municipio rural donde predomina el elemento económico, con un villicio o merino a su cabeza, con estructura ligada a la jura impersonal y al poder judicial; el municipio privilegiado, surgido por la aplicación de concesiones nobiliarias, infanzonías, etcétera, y el municipio consular, desarrollado en Italia y en el sur de Francia, con la justicia separada dependiente del rey y designado como communitatem seu commune, con la curiosa evolución de los podestá italianos, que simboliza la imparcialidad de los gobernantes. Hay también tipos intermedios, como las ciudades del señorío, en las cuales participaban los vecinos junto con el delegado del señor. ${ }^{3}$

2 María Hernández, Antonio, Derecho municipal, teoría general, vol. I, Buenos Aires, De Palma, 1984, p. 86.

3 Ibidem, p. 89. 
Concretamente en España el municipio representó un elemento vital para consolidar la expulsión de los árabes del territorio conquistado. Conforme los reyes en Navarra, León, Castilla o Aragón conseguían recuperar territorios a los moros, inmediatamente se otorgaba la autonomía municipal a los habitantes respectivos o se fundaban nuevas villas con el objeto de que sus habitantes hicieran frente a los árabes. ${ }^{4}$

\section{SISTEMAS DE GOBIERNO MUNICIPAL}

La herencia histórica, así como las diversas tradiciones locales en Europa motivan la aparición de diversas figuras políticas y administrativas de los gobiernos locales. En particular los sistemas de gobierno municipal tienen en común la existencia de un órgano popular colegiado, el cual se le denomina ayuntamiento, concejo o comisión. Por lo tanto el órgano colegiado representa el antecedente para elaborar la clasificación de los sistemas de gobierno, ya que su estructura orgánica presenta diferentes formas en cuanto a su número de integrantes, su organización interna y sus atribuciones. ${ }^{5}$

\section{Gobierno por comisión o asamblea}

En este caso el gobierno local se encuentra en poder de concejos electivos populares y el estado cuenta con escaso control en los asuntos municipales. Esta forma de gobierno se estableció en consecuencia del principio del self-government, el cual nace como consecuencia de la Revolución inglesa de 1689.

4 Ejemplo de tales concesiones fueron: el Fuero de León, concedido por Alonso V (a. 1020); de Nàjera, capital de La Rioja, dado por el Rey de Navarra Sancho el Mayor (en el a. 1076 confirmado por Alonso VI); de Sepúlveda, otorgado por Alonso VI (a. 1076), extendido a Roa (1143) y Teruel (1176); el de Logroño concedido por Alonso VI (1095), extendido a Vitoria por Sancho el Sabio de Navarra (1181) y Bilbao (1300); el de Sahagùn, otorgado por Alonso VI (1085); de Toledo, dado por Alonso VII (1118), extendido después a casi todos los pueblos conquistados por el Santo Rey don Fernando, como Córdoba, Sevilla, Murcia, Niebla, Carmona y otros; de San Sebastián, en Guipúzcoa, dado por Sancho el Sabio de Navarra (1150); el de Cuenca, dado por Alonso VII (1190); el de Cáceres, otorgado por Alonso IX (1229); entre los más destacados. Véase: Ibidem, pp. 94-95.

5 Zuccherino, Ricardo Miguel, Teoría y práctica del derecho municipal, Buenos Aires, ed. De Palma, 1986, pp. 75-85. 
La característica principal consiste en la elección de un cuerpo colegiado, el cual tiene la responsabilidad primaria en materia política y administrativa del municipio. Este sistema municipal evolucionó rápidamente ante las necesidades propias de las poblaciones urbanas. Por lo que el concejo delegó en un funcionario las competencias administrativas y se reservó para sí las decisiones de los asuntos políticos fundamentales.

El gobierno por asamblea pronto quedo en desuso en Inglaterra ante el crecimiento de las ciudades. Sin embargo, esta figura municipal se vuelve a introducir bajo la forma de gobierno por comisión en el puerto de Galveston, Texas, en 1901. En la nueva versión el gobierno se encomienda a cinco representantes públicos por un período de dos o cuatro años. Sobresale el recurso de la revocatoria popular del mandato en caso de un mal desempeño de las responsabilidades de los anteriores representantes. Para el año de 1953 el 15\% de los gobiernos locales en Estados Unidos de América se inclinaba por el sistema de asamblea.

En nuestro continente americano el sistema por comisión presenta dos variantes. La primera se distingue en virtud de que la comisión ejecuta en conjunto las funciones normativas y reparte entre sus integrantes las atribuciones de gestión o administración. El sistema es el más común en Estados Unidos de América y también tiene aplicación en las provincias de Santa Fé y Tucumán en Argentina. El segundo sistema se caracteriza en razón de que la comisión en forma conjunta realiza todo tipo de competencias públicas. Variante que tiene aplicación en Tegucigalpa, Honduras y en las provincias de Jujuy y San Luis en Argentina.

\section{Sistema de concejo y asamblea administrativa}

El concejo municipal es electo popularmente y cuenta con la facultad para nombrar una asamblea administrativa que se encargue de ejecutar las decisiones del concejo. Este fue el siguiente paso del primer tipo de gobierno en Inglaterra. En dicha nación la estructura de los gobiernos locales ha sido regulada por diferentes cuerpos legales como The Municipal Corporation Act de 1882 y el Local Government Act de 1933.

En dichos ordenamientos se establece como responsable del gobierno al concejo municipal, cuyos integrantes surgen de votación popular y tienen un mandato de tres años. El concejo municipal elige una comisión permanente de administración, compuesta por un número variable de integrantes, 
denominados aldermen y seleccionados en razón de especialidades en la problemática municipal. Además, el concejo cuenta con la facultad de elegir diversos funcionarios técnicos, entre ellos al secretario municipal o townclerk.

La comisión de administración la preside el mayor, quien tiene la representación del municipio y cuenta con ciertas facultades ejecutivas y judiciales. La asamblea de administración se encuentra subordinada al concejo municipal y sus miembros pueden ser cesados en cualquier momento.

- Aunque todos los municipios ingleses tienen la misma estructura jurídica y orgánica, en atención al aspecto geo-económico existen cuatro tipos diferentes de municipios:

- El burgo-condado o country borough.

- El burgo-municipal o municipal borough .

- El distrito urbano o urban district council.

- El distrito rural o rural district council.

Cabe aclarar que el modelo de gobierno en cuestión, también conocido como del concejo y mayor, fue el que inicialmente se utilizó en los Estados Unidos de América. Sin embargo, en muy pocos años éste evolucionó para otorgar a los votantes el derecho de elegir al mayor.

\section{Sistema bicameral europeo}

El bicameral es característico de las modernas democracias europeas. Su estructura consta de dos organismos colegiados y uno unipersonal, ambos con personalidad jurídica. El primer organismo colegiado o cámara alta es el que cuenta con mayor importancia política. Se integra a partir de elecciones populares y se le denomina concejo municipal en Italia y Portugal, o ayuntamiento en España. Cuenta con la mayor representación y tiene bajo su competencia la función legislativa y el control de la cámara baja del municipio.

La cámara menor tiene diversas formas de organización. En Bélgica y Holanda se integra por miembros de la asamblea principal. En países como Portugal y Suecia se integra por funcionarios profesionales electos por la cámara alta. En todos los casos la asamblea menor realiza las competencias de administración municipal. 
El órgano unipersonal tiene a su cargo la ejecución de las decisiones de la asamblea municipal y debe apoyarse en la cámara menor en lo que respecta a las funciones administrativas. Su denominación cambia conforme al país europeo que se estudie, por ejemplo en Italia recibe el nombre de sindaco o alcalde y en España el de presidente municipal.

\section{Sistema de concejo y gerente}

Nace en Estados Unidos como fórmula para encontrar un gobierno con mayor eficiencia administrativa respecto del gobierno municipal por comisión. "Munro señala que la primera ciudad importante, que empleó la idea de Manager fue Dayton, Ohio, luego Springfield -Ohio también y posteriormente Norfolk, Porstmouth" ${ }^{6}$ El sistema de concejo y gerente ha tenido una difusión favorable en Norteamérica. De un $25 \%$ de municipios que contaban inicialmente con esta forma de gobierno aumentó a un 38\% en el período de 1953 a 1960. Además de que ha logrado difundirse en países como Canadá e Irlanda.

$\mathrm{Su}$ forma de gobierno consiste en la elección de una comisión que cuenta con la máxima responsabilidad política en el municipio. Por su parte la comisión designa a un gerente o manager que ejecuta y administra las decisiones de gobierno hechas por la misma comisión. El contrato de gerente es indefinido en cuanto al tiempo y la comisión se reserva el derecho de removerlo en cualquier momento. En cuanto al funcionamiento de la comisión, ciertas legislaciones establecen que el gerente presida la comisión y en la mayoría de ellas el cuerpo colegiado cuenta con facultades para proceder a la designación del presidente.

El gobierno por gerente también se ha extendido a Europa. A raíz de la Constitución francesa de 1958, de corte centralista, las comunidades han adoptado el sistema de asamblea deliberante o concejo municipal. La asamblea municipal es electa por un período de seis años y sus integrantes van desde 9 a 37 miembros, según el grado de importancia socio-económica de la comunidad. La asamblea cuenta con la responsabilidad política de la población y designa a un maire o alcalde para ejecutar sus decisiones. El alcalde es el agente del estado ante la comunidad, asume las funciones de

6 Rendón, Huerta, Teresita, Derecho municipal, México, Porrúa, 1985, p. 140. 
jefe de personal de gobierno y es el encargado de la policía comunitaria y judicial local.

El elemento democrático se encuentra garantizado en la elección ciudadana de la asamblea o concejo municipal, la cual realiza la función de establecer las políticas generales y supervisar los programas y servicios públicos del municipio. Por su parte, el gerente encuentra mejores condiciones para desarrollar las obras y servicios locales al no tener injerencia directa en los asuntos políticos fundamentales. Además, esta forma de gobierno ha demostrado que los servicios municipales son más económicos y eficientes que en cualquier otro sistema.

\section{Sistema americano de concejo y mayor}

En Norteamérica el mayor fue adquiriendo notable relevancia política, por ello las primeras reformas municipales se dieron en el sentido de que los habitantes tuvieran el derecho de elegir al mayor o alcalde.

Teresita Rendón señala con relación a su organización política:

Se trata de un régimen de división de poderes, las funciones municipales se distribuyen entre el Mayor, elegido por el pueblo - Ejecutivo-, y el Concejo, elegido también por el pueblo y con frecuencia compuesto de dos Cámaras: la primera aplicación de la separación de poderes se hizo, dice M. Maxey, en la Carta de Baltimore de 1797, que estableció un Mayor independiente y un Concejo Bicameral. Semejante innovación aparece pronto en otras ciudades, pero se discute entre los estudiosos si se produjo esto en principio como resultado de una deliberada aplicación de la doctrina de la separación de poderes y frenos y contrapesos al régimen municipal, o fue ello el resultado de diferentes factores... Lo incuestionable es que a mediados del siglo, la idea de la separación de poderes y de los frenos y contrapesos se había aceptado como principio fundamental en el gobierno municipal. ${ }^{7}$

Por tanto, el gobierno de mayor y concejo representa la continuidad o seguimiento del gobierno nacional en cuanto a la división de poderes. El primero tiene a su cargo las funciones ejecutivas como es el caso del control del presupuesto municipal y el nombramiento de los funcionarios administrativos. En cambio, el concejo municipal realiza las competencias legislativas ya que expide los reglamentos municipales respectivos.

7 Rendón Huerta, Teresita, op. cit., p. 142. 
Si se considera el desarrollo histórico y orgánico de los gobiernos municipales en Norteamérica, se puede apreciar que existen infinidad de variantes en la forma de ejercerlo. Sin embargo, a pesar de tal diversidad es posible clasificarlos todos ellos en una de las siguientes variantes: sistema de mayor fuerte y concejo débil o sistema de concejo fuerte y mayor débil.

El sistema de concejo y mayor es el que ha tenido mayor difusión en Norteamérica. A pesar de sus variantes orgánicas destacan como atributo la facultad de los ciudadanos para elegir a un ejecutivo unipersonal, llamado intendente, alcalde, mayor o presidente municipal, así como la elección de la asamblea, departamento, concejo o ayuntamiento municipal que cuenta con las atribuciones legislativas. El modelo se ha extendido a países como Argentina, Brasil, Cuba, Ecuador, Uruguay, Filipinas y España.

\section{EL MUNICIPIO EN LAS CONSTITUCIONES}

Contrario a lo que pudiera suponerse, las constituciones que tienen menor codificación de sus gobiernos locales presentan la mayor diversidad y, además, respeto por las prácticas políticas y administrativas del mismo. Al respecto se presenta en la tabla 1 una muestra de naciones para ilustrar este punto, comparando tanto naciones federales como centralistas, así como de diferentes extensiones territoriales.

Destaca en primer término la Constitución de Estados Unidos de América en la cual no se menciona ningún tipo de gobierno local, aplicándose la regla federalista en el sentido de que corresponde a los estados su reglamentación. La consecuencia es que en dicha Nación existe la mayor variedad de formas de gobierno local y, en todas ellas, existe un alto grado de autonomía política, financiera, administrativa y social (Nice y Fredericksen). ${ }^{8}$

En un segundo plano aparecen federaciones distintas como Canadá, Argentina y Alemania que reproducen una descripción mínima. El resultado ha sido la existencia de tipologìas municipales a lo largo de sus territorios, quedando bajo los estados federados la mayor parte de su reglamentación. En la muestra destaca Argentina por ser un país Latinoamericano y de sistema jurídico romano a diferencia de los anteriores que tienen raíces jurídicas distintas. Sobresale que en todas estas naciones existen formas de gobierno diferentes, como la presidencial (EUA y Argentina), semi-presidencial

8 Nice, David y Fredericksen, Patricia, The Politics of Intergovernmental Relations, 2a. ed., Chicago, Nelson-Hall Publishers, 1995, pp. 149-153. 
(Alemania) o parlamentaria (Canadá) sin que hubiese incidido sobre la organización municipal. Lo cual demuestra que el factor determinante para la existencia de la diversidad municipal ha sido la reglamentación constitucional.

En el caso Argentino, Daniel Cravacuore enfatiza como los diferentes tipos de municipios desarrollan programas diferentes en materias de salubridad, promoción empresarial, desarrollo urbano y educación, sin la obligación de que todos tengan que cumplir con las mismas responsabilidades. ${ }^{9}$ Respecto de Alemania Wollmann señala que la diversidad ha sido resultado de la fuerte tradición histórica de autonomía, así como la forma en que se ejerce la Administración Pública ya que al menos $80 \%$ de la legislación federal y estatal la ejercen los gobiernos locales. ${ }^{10}$

Los dos últimos casos corresponden a Brasil y México, en las cuales la excesiva reglamentación fundamental ha ocasionado la imposibilidad de introducir diferentes tipos de gobiernos municipales a pesar de la gran extensión territorial y diferencias socio-económicas en ambos países. Jorge Macon al comparar Argentina y Brasil señala que en la primera nación cada provincia reglamenta al municipio de acuerdo a su propio criterio, lo que ha originado un sistema diferente en cada provincia. En cambio, en Brasil la propia Constitución federal reglamenta los municipios estableciendo entre otras cosas sus funciones, su derecho de darse su propia ley orgánica y también sus recursos. ${ }^{11}$ Además, esta situación institucional ha favorecido las finanzas municipales en Argentina al tener una proporción de financiación mayor. ${ }^{12}$

En el caso de Chile, Colombia y Guatemala no se verifica la diversidad municipal. Esto obedece a la estructura centralista de estas naciones, así como por las dimensiones geográficas, siendo la tendencia general en la mayoría de naciones centralitas. Por su estructura administrativa, el gobierno local es una extensión del central.

9 Cravacuore, Daniel, El estímulo a la innovación en el gobierno local, www. sme. gba.gov.ar.

${ }^{10}$ Wollmann, Hellmut, Länder y Diversidad Local, Instituto de Ciencias Políticas y Sociales, Universidad Autónoma de Barcelona, 2001, p. 6.

11 Macon, Jorge, Relaciones Intergubernamentales en Brasil, documento presentado en CFI-Buenos Aires, 1996, p. 7.

12 Ibidem, p. 22. 
TABLA 1. LA REGULACIÓN CONSTITUCIONAL DEL MUNICIPIO

\begin{tabular}{|c|c|c|c|}
\hline Pais & Forma gobierno & $\begin{array}{c}\text { Artículos } \\
\text { de la Constitución }\end{array}$ & Tipología \\
\hline $\begin{array}{c}\text { Estados Unidos } \\
\text { de América, } \\
1787\end{array}$ & Presidencial, federal & No & Sí \\
\hline $\begin{array}{c}\text { Canadá, } \\
1867 \text { y reformas }\end{array}$ & $\begin{array}{l}\text { Parlamentario, } \\
\text { Federal }\end{array}$ & $8,16,92$ & Sí \\
\hline $\begin{array}{l}\text { Argentina, } \\
1994\end{array}$ & Presidencial, federal & 41, párrafo III, 22. & Sí \\
\hline $\begin{array}{l}\text { Alemania, } \\
1949\end{array}$ & $\begin{array}{l}\text { Semi-presidencial, } \\
\text { federal }\end{array}$ & 28 & Sí \\
\hline $\begin{array}{c}\text { Brasil, } \\
1988\end{array}$ & Presidencial, federal & $\begin{array}{l}\text { Capítulo IVDe los } \\
\text { municipios } \\
\text { Del } 29 \text { al } 31\end{array}$ & No \\
\hline $\begin{array}{l}\text { México, } \\
1917\end{array}$ & Presidencial, federal & $\begin{array}{l}\text { Artículo } 115 \text { De la Or- } \\
\text { ganización municipal }\end{array}$ & No \\
\hline $\begin{array}{l}\text { Chile, } \\
\text { Fecha: } 1980\end{array}$ & $\begin{array}{l}\text { Presidencial, } \\
\text { centralista }\end{array}$ & $\begin{array}{c}\text { Administración } \\
\text { comunal } \\
\text { (del 107 al 115) } \\
\text { (modificado por Ley } \\
\text { 19.097 de 1991 y Ley } \\
\text { 19.526 de 1997) }\end{array}$ & No \\
\hline $\begin{array}{l}\text { Colombia, } \\
1991\end{array}$ & $\begin{array}{l}\text { Presidencial, } \\
\text { centralista }\end{array}$ & $\begin{array}{c}\text { Capítulo III. } \\
\text { Del Régimen Municipal } \\
\text { Del } 311 \text { al } 321\end{array}$ & No \\
\hline $\begin{array}{l}\text { Guatemala, } \\
\text { 1985, reformas } \\
\text { de } 1993\end{array}$ & $\begin{array}{l}\text { Presidencial, } \\
\text { centralista }\end{array}$ & $\begin{array}{c}\text { Capítulo VII } \\
\text { Del Régimen Municipal } \\
\text { Del } 253 \text { al } 262\end{array}$ & No \\
\hline
\end{tabular}




\begin{tabular}{|c|c|c|c|}
\hline País & Forma de gobierno & $\begin{array}{c}\text { Artículos } \\
\text { de la Constitución }\end{array}$ & Tipología \\
\hline $\begin{array}{c}\text { España, } \\
1977\end{array}$ & Autónoma & $\begin{array}{c}137 \\
\text { Capítulo segundo } \\
\text { De la administración } \\
\text { local } \\
\text { (artículos } 140 \text { y 141) }\end{array}$ & Sí \\
\hline $\begin{array}{c}\text { Italia, } \\
1947\end{array}$ & Autónoma & $\begin{array}{c}\text { Título V } \\
\text { De las regiones, pro- } \\
\text { vincias y municipios } \\
\text { (artículos } 114 \text { al 119) }\end{array}$ & Sí \\
\hline $\begin{array}{c}\text { Francia, } \\
1958\end{array}$ & Centralista & $\begin{array}{c}\text { Título XII } \\
\text { De las entidades } \\
\text { territoriales } \\
72 \text { (Modificado } \\
28 / 03 / 2003 \text { ) }\end{array}$ & Sí \\
\hline
\end{tabular}

Fuente: Constituciones nacionales.

Sin embargo, en los casos de las naciones europeas la historia es distinta a pesar de que muchas sean centralistas. Se muestra el caso de dos naciones con autonomías como España e Italia, así como el caso de Francia siendo centralista. Tanto el peso histórico, así como el marcado aspecto cultural de los regionalismos han ocasionado la diversidad de los gobiernos municipales sin importar que sean naciones relativamente pequeñas, en comparación de las federalistas, o de sus marcos normativos con mayor peso político con relación a las instituciones centrales (Ruiz-Rico). ${ }^{13}$

La tendencia a la diversidad local se refleja inclusive en los sistemas de relaciones fiscales intergubernamentales. John Noregaard menciona que la teoría de las finanzas locales sugiere que la estructura orgánica óptima de un gobierno local consiste en una multitud de niveles de gobierno con diferentes jurisdicciones de acuerdo a los servicios ofrecidos. A este modelo de "caos organizado" corresponde Estados Unidos de América con la mayor diversidad de formas de financiamiento. En el lado opuesto se encuentran

13 Ruiz-Rico, Gerardo et al., Formas de gobierno y sistemas electorales, Tirant Lo Blanch, 1997. 
los países escandinavos en los cuales existe un sistema más purista de niveles claramente definidos. Francia, con un sistema de cooperación entre gobiernos locales, representa un sistema intermedio. ${ }^{14}$

\section{ANTECEDENTES EN MÉXICO}

Hernán Cortés funda en las costas indígenas de Chalchihuecán el Ayuntamiento de la Villa Rica de la Verdadera Cruz en 1519. Su propósito consistió en crear un medio para legitimar la Conquista y librarse de las órdenes directas de Diego de Velásquez, Gobernador de Cuba. Además de dicha finalidad la institución municipal también se utilizó para ir organizando la vida política, económica y administrativa en aquellos lugares conquistados por los españoles.

En la etapa de organización tenemos como legislación aplicable las "Ordenanzas de Descubrimientos, Población y Pacificación de Indias" de Felipe II en que se disponía la estructura municipal, asimismo eran señaladas las facultades de los adelantados o gobernadores y la determinación de las reglas a observar en el trazo y disposición ornamental urbana de las nuevas poblaciones. ${ }^{15}$

El municipio mexicano alcanzó una gran autonomía debido a su papel en la Conquista y, sobre todo, a la lejanía de España. Sin embargo, el declive de la autonomía municipal da comienzo con la reforma legislativa española que fundó doce intendencias en 1767. La reforma suprimió facultades a los ayuntamientos y otorgó mayores funciones en favor de la Junta Superior de la Real Hacienda, el virrey, los intendentes y los gobernadores. En especial se otorgó a los intendentes y gobernadores atribuciones políticas y administrativas directas en los ayuntamientos.

Dicha reforma legislativa tuvo como propósito inicial corregir los vicios de la organización administrativa de los ayuntamientos, ya que su estructura orgánica original no atendía a la nueva realidad de las villas y ciudades de la Nueva España. En específico se creó una contaduría general, se aumentaron

14 Noregaard, John, "Intergovermental Fiscal Relations," Tax Policy Handbook, Parthasarathi Shome, Fiscal Affairs Department, International Monetary Fund, 1995.

15 Rendón Huerta, Teresita, op. cit., p. 94. 
las responsabilidades a los funcionarios municipales y se disminuyeron los sueldos y gratificaciones de los mismos. ${ }^{16}$

El último antecedente jurídico del municipio colonial lo encontramos en "la Constitución de Cádiz, la cual al introducir las jefaturas políticas, copió al modelo francés, regulando la organización y funcionamiento de los ayuntamientos por el capítulo del título IV que lleva la denominación siguiente: Del gobierno y administración de los pueblos". ${ }^{17}$

En cuanto al municipio a partir de la época independiente, Teresita Rendón señala: "que la Constitución de 1824 en ninguna de sus partes hace referencia al mismo y deja en libertad a los Estados para que en su régimen interior adopten lo más conveniente" sin oponerse a esta Constitución ni al Acta Constitutiva (artículo 161, de la Constitución de 1824)". ${ }^{18}$ Al no haber reglamentación nacional de la institución municipal se dio libertad a las entidades federativas para organizarla conforme a sus necesidades, lo cual propició cierta autonomía política y administrativa en la mayoría de municipios.

Al contrario de las constituciones federales, las leyes nacionales centralistas fueron las que se preocuparon por otorgar al municipio un marco jurídico adecuado. Dicha preocupación legislativa originó la uniformidad y sujeción del municipio a las autoridades centrales de los estados, departamentos o intendencias. Al efecto las Bases Constitucionales de 1835 establecen la institución municipal bajo la figura política de las juntas departamentales y las Leyes Constitucionales de 1836 lo regulan bajo el mismo esquema jurídico en los artículos 22 al $31 .^{19}$

La Constitución Federal de 1857 restituye la regla general de reservar a los estados la facultad de organización interna. La nueva situación municipal vuelve a otorgar cierto grado de autonomía al municipio. Sin embargo, dicha autonomía vuelve a debilitarse al promulgarse las leyes de Reforma y diversas leyes administrativas expedidas bajo el mandato del presidente

16 Ibidem, pp. 96-98.

17 Ochoa Campos, Moisés, La reforma municipal, 4a. ed., México, Porrúa, 1985, p. 223.

18 Rendón Huerta, op. cit., p. 108.

19 “Articulo 22. Habrá ayuntamientos en las capitales de departamento, en los lugares en que los había el año de 1808, en los puertos cuya población llegue a cuatro mil almas, y en los pueblos que tengan ocho mil. En los que no haya esa población, habrá jueces de paz, encargados también de la policía, en el número que designen las juntas departamentales, de acuerdo con los gobernados respectivos". 
Porfirio Díaz. Al respecto Tena Ramírez menciona que "para acentuar la centralización y borrar toda autonomía municipal, el gobierno del general Díaz agrupó a los ayuntamientos en divisiones administrativas superiores que recibieron los nombres de partido, distrito, prefectura o cantón. Los prefectos de origen centralista, que fueron instituidos por la Constitución de 36 (artículo 17 de la Ley VI), eran los agentes del gobierno central del Estado". ${ }^{20}$ Así

las jefaturas políticas tuvieron, en la extensión del país, las siguientes características generales:

a) Representaban un tipo de autoridad intermedia entre el gobierno del estado y los ayuntamientos.

b) Estaban sujetas a la voluntad de los gobernadores.

c) Centralizaban y maniataban toda la actividad municipal.

d) Eran de carácter distrital y residían en las cabeceras de distrito o de partido, controlando a los ayuntamientos de su circunscripción.

Los vicios de esta institución fueron comunes: suprimir toda manifestación democrática y cívica de la ciudadanía; controlar las elecciones; cometer atropellos y abusos que llegaron a lindar con lo criminal. ${ }^{21}$

La reforma administrativa y política fue determinante para que el municipio estuviera completamente subordinado a distintas autoridades y no llegará a desarrollarse como la institución política primaria de la nación.

La Constitución de 1917, a diferencia de las anteriores constituciones federales, reglamenta la institución municipal en el artículo 115. La justificación de su reglamentación la encontramos en la aversión a la figura del prefecto político ya descrita anteriormente, así como la necesidad de darle seguridad jurídica y patrimonial para evitar que otras instancias de gobierno limitaran sus atribuciones. A pesar de esta reglamentación, el texto original dejaba margen para que los constituyentes estatales pudieran desarrollar verdaderas tipologías municipales. El texto original consistía en reconocer la personalidad jurídica, al ayuntamiento como máximo órgano de gobierno municipal, reglas mínimas sobre la elección y permanencia

20 Tena Ramírez, Felipe, Derecho Constitucional Mexicano, 22a. ed., México, Porrúa, 1989, p. 150.

21 Ochoa Campos, op. cit., p. 274. 
de las autoridades, así como disposiciones mínimas sobre el régimen administrativo y financiero. ${ }^{22}$

Sin embargo, las reformas constitucionales posteriores $(1943,1947,1953$, 1976, 1977, 1983 y 1987, 1999, 2001, 2008), en particular las impulsadas durante el sexenio del presidente Miguel de la Madrid, motivaron una mayor reglamentación municipal, señalando atribuciones precisas sobre las responsabilidades del gobierno municipal, reglas sobre la democracia municipal, aspectos administrativos y una lista precisa de las fuentes de financiamiento municipal entre otras de carácter administrativo. ${ }^{23}$ En cada ocasión la justificación de la reforma consistió en dotar al municipio de mayores atribuciones y certeza jurídica para fortalecerlo.

\section{CONDICIONES GEOGRÁFICAS Y ECONÓMICAS}

La población promedio en los 2,453 municipios asciende a 42,097 habitantes (Conapo, 2008). ${ }^{24}$ Sin embargo, la desviación estándar es de 360,221 personas, lo cual demuestra la gran disparidad frente a la media. Este dato se aprecia con sólo verificar los extremos. Por ejemplo, Santa María en Zacatecas tiene 2,601 habitantes; Dzoncauich en Yucatán 2,782; Abasolo, Nuevo León 2,746; o Progreso, Coahuila con 3,379 personas. En el extremo opuesto encontramos municipios como Monterrey, Nuevo León, 1, 133, 814 habitantes; Guadalajara, Jalisco, 1,600,940; Ciudad Juárez, Chihuahua, 1,313,338, o Iztapalapa, Estado de México, 1,820,888 habitantes. En los casos de la Ciudad de México, Guadalajara y Monterrey encontramos delegaciones y municipios con poblaciones como las citadas anteriormente en forma conurbana.

La diversidad también se refleja en otros indicadores. Por ejemplo, el ingreso promedio por persona anual ajustado en pesos en 2004 ascendió a $\$ 27,827$. Sin embargo, el ingreso es muy bajo en municipios como Tehuipango, Veracruz, \$5,847 pesos anuales; San Lorenzo, Oaxaca, con \$5,982; Chalchihuit, Chiapas con $\$ 6,939$, o Hueytlalpan, Puebla con $\$ 9,490$. En el caso de Chiapas y Oaxaca son varios los municipios que se encuentran por

22 Artículo 115 original de la Constitución de 1917 en: Secretaría General, Secretaría de Servicios Parlamentarios, Centro de Documentación, Información y Análisis, Subdirección de Información Sistematizada, H. Congreso de la Unión, 2008.

23 Secretaría General, Secretaría de Servicios Parlamentarios, op. cit.

24 Consejo Nacional de Población, http//www.conapo.gob.mx/, 2008. 
debajo de la cifra de $\$ 10,000$ pesos por persona anuales. Entre los municipios con altos ingresos por persona encontramos a Tijuana, Baja California, \$83,748; Metepec, Estado de México, \$86,023; León, Guanajuato, \$92,539; San Pedro G., Nuevo León, \$166,787; o la delegación Benito Juárez, DF, con $\$ 186,314$.

En cuanto a la población económicamente activa (PEA) en promedio el $44 \%$ de la población municipal se ocupa en el sector primario, $23 \%$ en el secundario y $31 \%$ en el terciario. Aunque dichas cifras son un promedio, sobra decir que los municipios urbanos y con mayor riqueza son los que tienen mayor proporción de población en los sectores secundario y terciario.

En el aspecto cultural destaca el dato de la población indígena. De una población total de 91 millones de habitantes, 5.4 millones $(6.8 \%)$ son considerados nativos de la cultura prehispánica (INEGI, 92) ${ }^{25}$ De acuerdo al Instituto Nacional Indigenista estas culturas comprenden 56 grupos étnicos, asentados principalmente en los estados del sureste como Chiapas, Oaxaca, Veracruz, la península de Yucatán y Puebla. Al respecto se encuentran municipios donde prácticamente toda la población es indígena, como el caso de San Antonio, Quintana Roo con 77\%; Ocotepec, Chiapas con 80\%; Timucuy, Yucatán, 85\%; o el caso de Mixistlàn, Oaxaca con 86\%. Lo cual contrasta con la mayoría de municipios en el país donde la población nativa no representa un porcentaje importante.

\section{ANÁLISIS CONSTITUCIONAL}

El análisis constitucional tiene la finalidad de verificar la procedencia de la reforma consistente en la abrogación total o derogación parcial del artículo 115 de la carta fundamental, así como sus consecuencias jurídicas.

\section{Abrogación}

La primera alternativa consiste en la abrogación o eliminación total del artículo 115. Sobre la presente cuestión surgen dos problemas fundamentales: el alcance de la reforma constitucional y las consecuencias jurídicas en caso de que sea viable la misma. En el primer caso el artículo 135 señala que: "La presente Constitución puede ser adicionada o reformada". Si atendemos al

25 Instituto Nacional de Estadística y Geografía, http//www.inegi.gob.mx/, 2005. 
sentido literal llegamos a la conclusión de que el poder revisor del texto fundamental no puede eliminar ningún principio constitucional, sino añadirle aspectos nuevos o modificar los ya existentes. Desde este punto de vista no sería posible efectuar la eliminación del artículo. Sin embargo, la interpretación que pudiera justificar la abrogación consistiría en considerar el concepto de "reforma" en sentido amplio y reconocer que una de sus acepciones fuera la de anular o eliminar artículos. Al respecto Tena Ramírez opina que "el sentido gramatical de las palabras no puede ser una barrera para dejar a un pueblo encerrado en un dilema sin salida" ${ }^{26}$

Además, se han dado numerosos ejemplos en los cuales mediante la "reforma" se efectuaron verdaderas abrogaciones a ciertos artículos constitucionales. Por ejemplo, se encuentra abrogado el artículo 2 del texto original de la Constitución, el cual prohibía la esclavitud y se crea el vigente que reconoce la composición pluricultural de la Nación (DOF del 14 de agosto de 2001). El artículo 25 original garantizaba que la correspondencia que bajo cubierta circule en las estafetas, estará libre de todo registro. Se abrogó dicho texto y ahora se consagra que corresponde al estado la rectoría del desarrollo nacional (DOF del 3 de febrero de 1983, 6 de octubre de 1983 y 28 de junio de 1999). El 26 otorgaba la garantía de que en tiempos de paz ningún miembro del ejército podía alojarse en casa de particulares. El texto vigente establece la obligación del estado de organizar un sistema de planeación democrática del desarrollo nacional, el cual sirve de fundamento para los planes sexenales de gobierno (DOF del 3 de febrero de 1983). La redacción original del artículo 99 señalaba que el cargo de ministro de la Suprema Corte de Justicia de la Nación sólo era renunciable por causa grave. El contenido vigente establece y organiza el Tribunal federal electoral ( $D O F$, del 22 de agosto de 1996). El artículo 100 reglamentaba las licencias de los ministros. En la actualidad, se consagran los principios del Consejo de la Judicatura Federal (DOF del 31 de diciembre de 1994). Por su parte el 122 obligaba a los poderes de la Unión a proteger a los estados contra toda invasión o violencia exterior. El texto vigente consagra los principios del gobierno del Distrito Federal (25 de octubre de 1993). ${ }^{27}$

Sin embargo, la abrogación completa eliminaría el imperativo de adoptar una forma de gobierno republicana representativa y popular a las entida-

26 Tena Ramírez, op. cit., p. 58.

27 Secretaría General, Secretaría de Servicios Parlamentarios, op. cit. 
des federativas. Sánchez Bringas comenta que la autonomía de los estados se ve limitada con la finalidad de preservar los principios fundamentales del gobierno nacional para que exista congruencia entre dichos niveles de gobierno. ${ }^{28}$ Para evitar el problema la propuesta consistiría en conservar dicho principio del artículo 115 dentro del artículo 116 y eliminar completamente la referencia a la reglamentación y organizacional municipal. La otra opción consistiría en la derogación parcial del mismo 115 conservando únicamente el postulado ya aludido.

La segunda cuestión jurídica representa la posibilidad de considerar ilegales a los gobiernos municipales por no encontrarse fundamentados en la Constitución nacional. Al respecto nuestra Constitución contiene el principio federal, entre otros, como parte de la forma del Estado mexicano. Lo cual equivale a reconocer la soberanía de dos niveles de gobierno y reglas básicas para dividir las atribuciones de cada nivel. Regla que se encuentra en primer término en el artículo 41 que estipula que la soberanía se ejerce por los poderes de la Unión y por los de los estados, en los términos establecidos por la Constitución nacional y las respectivas de los estados. Posteriormente el artículo 124 introduce la regla más importante del federalismo, señalando al respecto: "las facultades que no están expresamente concedidas por esta Constitución a los funcionarios federales, se entienden reservadas a los estados". Esto quiere decir que el campo de acción para los constituyentes de las entidades federativas, así como las autoridades estatales, radica en todas aquellas materias que no fueron incluidas en la Constitución nacional en favor del gobierno federal.

Salvador Valencia, entre otros, admite esta posibilidad al señalar las reglas del federalismo. Señala el principio de la distribución de competencias (artículo 124) y, en consecuencia, el campo de la autonomía de los estados (artículo 41) mientras no exista contravención a las estipulaciones del pacto federal. ${ }^{29}$

Pacto que conlleva a que todas aquellas instituciones, organismos, prácticas, órganos, competencias o facultades de autoridades que no fueron contempladas en el texto nacional, encuentran su fundamento constitucional y jurídico en el principio ya mencionado (artículos 41, 124 y 73

28 Sánchez Bringas, Enrique, Derecho constitucional, 4a. ed., México, Porrúa, 1999, pp. 323 y 324 .

29 Valencia Carmona, Derecho constitucional mexicano a fin de siglo, México, Porrúa, 1995, p. 291. 
principalmente) además de su fundamentación en las constituciones y leyes secundarias estatales respectivas. Siendo éste el caso de la propuesta. Al abrogarse el contenido del artículo 115 no habría falta de validez constitucional ya que la materia en estudio recaería en las constituciones estatales. A la fecha todas las constituciones estatales reconocen el municipio y su gobierno, evitándose así una posible falta de validez jurídica si se promulga la reforma en comento.

\section{Derogación parcial}

La segunda opción consiste en establecer una declaración mínima en el texto del artículo 115 en la cual únicamente se estipule o reconozca la existencia del municipio como tercer nivel de gobierno sin otro tipo de reglamentación. Aquí opera nuevamente el principio de aquellos postulados no reglamentados en la Constitución federal se entienden reservados a las entidades federativas. Todos los puntos no mencionados en un nuevo artículo 115, quedarían bajo la responsabilidad de los constituyentes locales.

Este tipo de reforma pudiera representar un compromiso intermedio ante las presiones políticas que pudieran desatarse por la probable incertidumbre de una abrogación total. Lo importante es que para poder incentivar la creación de diferentes gobiernos municipales sería la redacción de un nuevo artículo que contenga disposiciones mínimas. Al respecto el nuevo texto pudiera incluir como puntos torales:

- Conservar el imperativo de la forma republicana de gobierno para las entidades.

- Reconocimiento del gobierno municipal como tercer nivel de gobierno.

- Garantizar la figura del ayuntamiento como máximo órgano de gobierno.

- Catálogo mínimo, pero no exclusivo de fuentes de ingreso municipal.

- Autonomía en cuanto a su administración interna, sujeta a control posterior o extraordinario de la legislatura estatal.

- Participación mínima de las participaciones y aportaciones federales. 
Normatividad que pudiera representar un primer paso para garantizar una estructura mínima de este gobierno. La propuesta no menciona reglas democráticas ni de la forma de representar este gobierno o ejercer la administración pública. De tal forma sería posible que cada constituyente local pudiera adecuar los municipios a sus condiciones e, inclusive, dentro de un mismo estado crear diferentes tipos de municipios. Los tipos de servicios públicos también estarían en atención a las capacidades de cada uno.

\section{CONSIDERACIONES FINALES}

El municipio en México presenta igualdad institucional en virtud de la supuesta protección del mismo al reglamentarlo en forma excesiva en la Constitución. Situación que contrasta con la trayectoria histórica del mismo, así como la situación de muchas naciones con gobiernos locales diferentes.

Desde sus orígenes el municipio ha presentado diversidad para adaptarse a las costumbres locales. Desde Roma, pasando por la Edad Media, la expulsión de los árabes en España, así como la conquista en Nueva España, la institución municipal se utilizó no sólo como punta de avance militar o política, sino como institución para organizar la vida local conjuntamente con las costumbres de gobierno ya existentes.

En México, al iniciarse la vida independiente todavía se cuenta con cierta autonomía. Sin embargo, las constituciones centralistas inician el proceso de reglamentar al gobierno inferior y el presidente Díaz crea divisiones administrativas superiores al municipio. La Constitución de 1917 reglamenta la figura municipal bajo el argumento de garantizar su autonomía frente a cualquier nivel de gobierno intermedio. La sana intención ocasionó el inicio de la excesiva reglamentación. La característica principal de las reformas constitucionales en el siglo XX consistió en el aumento de atribuciones, competencias y facultades gubernamentales.

Situación que contrasta con las tipologías de gobiernos locales que presentan diferentes sistemas constitucionales. Destaca que en Estados Unidos de América, Canadá, Argentina o Alemania existe una gran variedad de formas de gobierno municipal y escasa codificación nacional. El caso opuesto lo encontramos en Brasil y México, que al darse la pormenorización del gobierno local ha originado la uniformidad del mismo en todo el territorio sin importar las diferencias políticas y sociales. Inclusive en naciones centralistas europeas se reconoce la diversidad municipal. Las ventajas en 
estas naciones van desde la adecuación de los servicios a sus necesidades, mayor democracia y mayor financiamiento.

Al respecto se estableció como hipótesis de trabajo que la abrogación o derogación del artículo 115 de la constitución mexicana permitiría la diversidad municipal. El análisis jurídico demuestra la factibilidad del planteamiento. En ambos casos opera el principio federalista con diferentes intensidades. En el primer caso la consecuencia es que al reconocerse la soberanía de las entidades federativas, quedaría totalmente bajo su responsabilidad la reglamentación del municipio y su gobierno, ocasionando la mayor flexibilidad y, consecuentemente, proliferación de diversas formas de gobierno municipal. Mediante la derogación parcial se reproducirían principios genéricos para garantizar su existencia y la legislación estatal le correspondería su pormenorización.

En ambos casos la consecuencia sería una mayor proliferación del constitucionalismo local. Circunstancia que llevaría a la promulgación de una ley orgánica municipal con diferentes capítulos de gobierno, diferentes leyes orgánicas municipales que se otorguen en atención a categorías de municipios, o, en el caso extremo, cartas municipales individuales para poder introducir una variedad municipal real. Por lo que sería posible adaptar los marcos legislativos y reglamentarios de acuerdo a las diversas condiciones sociales y económicas que se presentan. En forma indirecta Daniel Moreno avala esta línea de acción al reconocer la eficiencia de los gobiernos municipales en Estados Unidos de América debido a su diversidad y flexibilidad para prestar servicios. ${ }^{30}$

La finalidad principal no consiste únicamente en promover el constitucionalismo local sino que al existir formas diversas sea posible ofrecer mejores servicios de acuerdo a las necesidades propias, promover diversas formas de participación ciudadana y contar con mejores estructuras administrativas. En este orden de ideas, la primera ventaja sería en corregir el desequilibrio entre los municipios que demandan mayores responsabilidades y de aquellos que no pueden con las que actualmente señala la Constitución. De esta forma se podría señalar que cada municipio tendría un traje a la medida de sus necesidades. En el aspecto fiscal sería posible también aumentar las bases para los municipios con mayores recursos y crear sistemas de transferencias fiscales más adecuados. Al respecto Cabre-

30 Moreno, Daniel, Derecho constitucional mexicano, 11a. ed., México, Porrúa, 1990, p. 371 . 
ro y Carrera mencionan que la estructura institucional, así como el marco legislativo representan una parte de las variables que explican las grandes diferencias y carencias financieras entre los municipios. ${ }^{31}$

En el caso de la abrogación otra consecuencia consistiría en la posibilidad de crear distintos tipos de autoridades locales con diferentes niveles de sujeción al gobierno estatal o municipal y con estructuras administrativas distintas. En tal caso podríamos señalar la creación de figuras de gobierno locales de acuerdo a materias o necesidades en particular. Por ejemplo, en materia de agua, parques y jardines, basura, cultura, educación básica (distritos educativos), tránsito y materias similares y que tienen un ámbito estrictamente local.

Estos gobiernos o entes locales podrían ser creados sin que pertenecieran directamente al ayuntamiento y quedar subordinados en una segunda instancia de control y evaluación por las autoridades estatales y/o municipales. En el caso de la derogación parcial, si el nuevo artículo no contempla los servicios y materias correspondientes al gobierno municipal, la presente propuesta tendría la misma efectividad al poder crear el constituyente local la diversidad de gobiernos y entes administrativos. Entre sus ventajas se presenta la flexibilidad para otorgar servicios, la posibilidad de que los límites jurisdiccionales pueden trascender los municipios $u$ otras autoridades y conjuntar recursos regionales. ${ }^{32}$

El planteamiento también evitaría la creación de gobiernos municipales centralistas o con enormes dimensiones, con las consecuencias burocráticas, mal servicio y fiscalmente más onerosos. Al permitirse la variedad de autoridades locales se permite la especialización, mejores servicios al ciudadano, así como mayor participación de los usuarios de los servicios.

${ }^{31}$ Cabrero, Enrique y Carrera, Ady, Fiscal Decentralization and Institutional Constraints. Paradoxes of the Mexican case, Documento de Trabajo, DAP-CIDE y Fundación Ford, 2001, p. 30.

32 Nice y Fredericksen, op. cit., p. 153.

Fecha de recepción: 24 de febrero de 2010.

Fecha de dictamen: 9 de agosto de 2010. 